after the tightening of the ligatures, very nearly limited to that conveyed by the left carotid and by the branches given off by the first part of the right subclavian.

The history of this case proves, with those to which I have alluded, and cases subsequently treated by $\mathrm{Mr}$. Barwell, that even where the disease is so extensive the distal operation very greatly alleviates the symptoms, and, when the patient is moderately careful, may indefinitely prolong life. Hull.

\section{ON THE TREATMENT OF PHTHISIS AT DAVOS AM PLATZ.}

\section{BY DR. CLIFFORD ALLBUTT.}

IN the autumn of last year I published the impressions I received from a visit paid to Davos am Platz in the Grisons in the preceding summer. ${ }^{1}$ As the time for the summer residence is rapidly approaching, it seems desirable that I should state the results of my experience of Davos during the past winter, and add any words of advice which are likely to be useful to persons who intend to visit Davos in the coming season.

In my former paper I gave some account of the situation and climate of Davos, and of the curative work I saw in progress there. I did not hesitate to say that the results there obtained, especially in phthisis, seemed to me to be far in advance of those secured at any other health-resort, and I ventured to suggest an interpretation of the results apparently obtained. For many years I have held that the majority of phthisical patients die of septicæmia, and that the arrest of this daily repoisoning is a primary object of treatment. To reach, cleanse, and dress ulcers of the lungs by surgical methods seems impossible, and the effects of antiseptic inhalations are disappointing; if, however, there be an antiseptic climate, we may hope to counteract this secondary blood-poisoning by sending our patients to live in it. Such antiseptic or aseptic climates are found in Switzerland, in Upper Egypt, and in other districts; and in the mountain air of Switzerland there is found also a tonic virtue which no doubt largely aids the physician in his work. The aseptic state of the air on alpine heights has been proved by Professor Tyndall's experiments at the Bel Alp; but the Bel Alp, in common with most other alpine resorts, is insufficiently sheltered. In Davos alone, so far as we yet know, is found an air at once aseptic, bracing, and still. Upon these points I must refer the reader to my former paper. Very few English invalids have as yet found their way to Davos, and observations based upon the cases of English invalids are therefore not many. During the past winter my friend Dr. Rüdi has treated nineteen cases among the English; some of these were patients of my own, and others had been seen by me. Dr. Rüdi has kindly sent me notes of all. Of these nineteen, nine were cases of pulmonary disease. ${ }^{2}$ Shortly put, they fared as follows :-

CASE 1.-Arrived on August 6th, 1877. Large cavity in upper lobe of left lung below the clavicle, infiltration of the whole lobe, and moist râles all over the left lung. Ordered to keep quiet, sit out in the fresh air, take abundant food and milk, and wine twice daily. Soon strength was restored, perspirations ceased, fever ceased, and appetite returned. At the end of December came on an attack of bronchitis in the whole left lung and renewed fever; this attack lasted four weeks. Recovery was satisfactory; respiration in the lower lobe became normal, and the cavity almost ceased to secrete. The surrounding tissue is still infiltrated, but shows no sign of irritation. The cavity is contracting. Next winter it will close. Although this patient has to return to Davos good progress was made; for on arrival the disease was still progressing and liquefaction rapidly at work.

CASE 2.-Came with infiltration of the right apex and

1 Vide THE LANCEx, October 20th and 27th, 1877.

2 These cases are purposely divested of personal data, as in a society like that of Davos each is known to all. Full particulars of the cases are, however, on record, and will be gladly supplied to any medical man who wishes for them. adhesions of the right lung to the diaphragm after pleuro. pneumonia. Perfect recovery in five months.

CASE 3.-Had a very large cavity in the right lung, extending into both upper lobes; moist râles all over the right lung, infiltration being extensive. In four months expectoration diminished to one-third, and strength and weight were gained. There was no inherited disposition. The process being now arrested and the cavity closing, recovery may be expected next winter.

CASE 4.-Convalescent from a pneumonia. No infiltration. Very feeble breathing, and imperfect expansion of left lobe. Donches used. Recovery perfect.

CASE 5. - Course exceptional. The appetite improved directly on arrival, sleep returned, fever and night-sweats ceased, and there was no diarrhoea. The state of the lungs also much improved. But this patient lost constantly in weight. $\mathrm{He}$ is a medical man, and says of himself, "in every other respect I made a splendid cure, only the constant loss of weight frightens me." [I may add that this gentleman saw me late in the year, and I would have dissuaded him from going so late to Davos; but he, knowing too well the probable course of his malady, stopped me, saying quietly he had determined to go. Both lungs were diseased, but I have not the exact notes at hand.-T. C. A.]

CASE 6 is one in which I (T. C. A.) am deeply interested. I shall give hereafter some extracts from letters this gentle. man has written to me. I urged him decidedly to spend the winter at Davos rather than proceed to Egypt as he had intended. He had cavities at one apex and infiltration at the other. He had been a poitrinaire for four years, and when he reached Chur could scarcely walk up to his bedroom. His hectic was continuous and severe. Dr. Rüdi now reports of him :- "After staying here another winter he may return to England, although the infiltration at the back part of the left apex will not have fully disappeared." I shall, as I have said, speak further of Case 6 .

The two following cases died.

CASE 7.- Had come to me (T. C. A.) for many months in $1876-7$, in hopeless phthisis. Both lungs were extensively involved, and he had been repeatedly in bed with inter. current pneumonia. There were other reasons for despairing of his state, among them great anxiety and pressure of business. As his life was very valuable I named to him last October the chance Davos might give him, and I put fairly before him the risks and the liopes. He decided to go on his own responsibility, and I described his going to his friends as a bold stroke for life. The patient wrote to me several times in good spirits, and assured me how much better he was. His appetite and his strength improved; his fever diminished, but never ceased. It was normal some days, but it would then run up in an evening to $100^{\circ}$ to $101^{\circ} \mathrm{F}$., and Dr. Ruidi always found the physical signs gaining ground rather than giving way, and wrote to me without holding out any hope. He died in the middle of February, but his departure from England is not wholly to be regretted, as he certainly suffered less than he had done at home.

CASE 8.-Came to Davos on Dec. 20th, 1877, with both lungs infiltrated, the right more extensively. In right middle lobe a cavity. Fever considerable, $102^{\circ}$ to $104^{\circ}$, commonly $1035^{\circ}$. This never diminished. Death occurred on March 20th following. It was a lost case when patient arrived, and should have been sent much earlier in the year if sent at all.

CASE 9.-Arrived Aug. 6th, 1877, very ill. Insufficiency of mitral valves after rheumatic fever; there was also catarrhal state of the right apex. This was therefore a complicated case. Patient gained weight, recovered well, and was sent home cured as regards his lung.

The rest of the cases contain no phthisis, and are as follows :-

CASE 10.-When at Davos I thought the patients had, for the most part, an air of well-being, but Mr. _- on the contrary, looked wretchedly weak, pallid, and ill. Mr. subject to catarrh of the stomach, came to Davos Aug. 25th, 1877, aged twenty-five, and left again on April 3rd, 1878 The patient writes as follows :- For years he had suffered from chronic dyspepsia, debility, constipation, headache, \&c. In March 1876, was put under a "vegetarian-starvation" diet. In three months lost three stones and a half in weight, and could not rise from bed. Rallied under different treatment, but never regained power of digesting food without great pain and distress. Thus from July, 1876, to June, 1877. Then went to Aix-la-Chapelle, and for six weeks had stomach washed out every morning before breakfast by 
the stomach syphon. Great relief followed at first, then fell back in all respects, and was very ill. On arrival at Davos had great pain and discomfort after food, gnawing pains in the stomach and arms, \&c.; appetite capricious; cold liquids "cut the stomach like a knife"; obstinate constipation. unable to move for three hours after a meal; quite unable to read or write, or even to listen to reading. By November was able to walk five hours a day; could take much more food, and with less discomfort. By April, altogether much stronger, able to read and write, and take plenty of exercise. Could now drink cold liquids at meals, and was in most respects wonderfully better. Digestion remained, however, weak, and diet had still to be restricted to plain meat and bread, and a little fruit. Weight: Aug. 21st, 1877, 7st. 2lb.; Sept. 21st., 7 st. 9 lb.; Oct. 19th, 7 st. $12 \mathrm{lb}$; Nov. 26th, 8 st. 2 lb.; Dec. 25th, 8 st. 6 lb.; Jan. 22nd, 1878, 8 st. 11 lb.; March 1st, 9 st. $6 \mathrm{lb}$.

CASE 11.-Arrived Nov. 15th, 1877. Hyperæmia of liver; nervous excitement, nocturnal emissions, headache, and debility. Ordered sal. therm. Carol., iron with nux vomica, cold rubbings, and douches. Left on April 10th, a great deal stronger, but not quite recovered.

CASE 12.-Arrived on Sept. ]4th. Old catarrh of rectum, piles, and recurrent dyspepsia. Ordered cold douche, exercise, and diet. Recovered, and left April 5th, 1878.

CASE 13.-Hysteria, neuralgia, slight anteflexio uteri. Left much better than she came, but scarcely fully recovered.

CASE 14. - Catarrh of the bowel. This case Dr. Rïdi regards as really incurable, and says she is no better. Patient, however, thinks herself wonderfully stronger, and has been able to enjoy life and to take exercise in a measure unknown to her before her arrival. [T. C. A.]

CASE 15.-Chronic dyspepsia and nervous debility and depression. [Sent by me at his own suggestion.-T. C. A.] He left Davos in a very good state of health, and his de pression probably will not return. This gentleman had travelled to many health resorts without relief.

CASE 16. - Hysteria, anæmia, and neuralgia in a young girl. Ordered milk, exercise, douches. Gained weight considerably. Sent home in five months, cured.

CASE 17. - Nervons headache and nocturnal emissions produced by mental work. Ordered exercise, douche, and nux romica. Perfect recovery.

CASE 18. - Hepatitis chronica. Ordered Tarasp water and exercise. In two months left, much relieved, not quite recovered.

CASE 19.-Melancholia supervening on nocturnal emissions and mental strain. Too nervous to stand douches, and was sent to Baden to take them. $\mathrm{He}$ is there under treatment.

I have thought it desirable to include all the English cases under treatment, though of course many of these miscellaneous cases are of little value. As a rule, perhaps, nervous diseases would do as well or better elsewhere, but they may serve to illustrate the tonic effects of the climate and the ease with which a winter is tolerated at a height of 5000 feet.

In accordance with my purpose, I now give some extracts from the letters received from the patient indicated as Case 6. I may be permitted to state that his evidence is of the highest possible value. In a letter dated Dec. 31st, 1877, Mr. X. says: "I have gone on, so Rüdi says, steadily improving, and he told me last Saturday that the cavity was beginning to close. There is certainly a depression in the surface above the place where it is supposed to be. I can walk a matter of from six to eight miles in favourable states of the atmosphere-i.e., when it is at the coldest and stillest,--doing this work in five hours. I have acquired the habit of walking very slowly. I have had several little colds, which have all passed off without much trouble. In the course of one catarrh I began to spit blood-streaks after exercise, but a few days' resting removed this symptom My temperature hardly ever rises above the normal, and then I do not think it has touched $100^{\circ}$ more than once.

I sleep fairly well, and have a really sound appetite, though I find the digestion rather difficult to keep in order. 'This is probably due to monotony of diet and want of change in the case of one who, like myself, has never spent three months in the same place since he was thirteen. My spirits are excellent, in spite of the unutterable ennui of the promenades and want of society. In this respect Davos seems to me to beat all health places I ever tried. They have always depressed me after a sojourn of a few weeks. Davos agrees capitally with my wife and children and all our party." In a letter dated "Feb. 6th, 1878, barometer in sun $141^{\circ} \mathrm{F}$., overpoweringly blazing," Mr. X. says : "You are welcome to use any parts of my letters if they can be of the least service to you." On Case 7 he comments as follows: "Poor - has gone steadily down-hill ever since he came here. One thing I feel inclined to remark, $\dot{\alpha}$ propos of his case, is that he came too late in the season. It was quite cold when he arrived, and he never gained strength enough to be able to take exercise. Exercise is, I am sure, the very soul of the winter cure. A really debilitated patient ought to come here in the early half of August, and if he cannot get up his strength by the middle of November to leave before the snowfall....... I am sure that really bad invalids coming here should be advised, at any cost, to get south rooms and a large room. Many people seem to me to suffer from crowded sitting-rooms and from sleeping in north rooms. Unless they approximate, at any rate, to the ideal in this respect, $I$ have a strong instinct they will not give Davos a fair chance. We have had a large proportion of days this winter when even an invalid so comparatively active as I am had to keep the house. Then the question of rooms is serious." In some interesting passages in another letter, Mr. X. wonders whether the very rest to the emotions obtained by residence in "quiet and non-human circumstances" does not help to work out a cure, and whether emotional impressions do not tend to have a directly injurious effect upon a diseased organ.

Another able correspondent writes to me on Feb.9th, 1878 : "No doubt you think there must be a great deal of time for letter-writing here, but I assure you it is not so; the days are not half long enough for all one wants to do; then, of course, ont-door exercise and amusements take up a good deal of the day, as one feels that to be in the open air as much as possible forms much of the whole duty of man. It. is said by regular Davosers that this has been an exceptionally bad winter. We have had so much snow and bad snowstorms, lasting three or four days. Yet the days on which we have not been able to go out at all have been few and far between. Even my invalid sister (Case 14) has often taken her constitutional on the boarded terrace while it has been snowing fast ; and we have had the most glorious days to repay us for any amount of snow. Since this month began it has been splendidly fine, with the exception of a little snow on one morning. Consequently we have been skating, sledging, and expeditioning as much as possible. You may imagine how much better my sister is, or she could not be equal to such excursions. I am thankful to say she is decidedly better. Though she still suffers from pain in her head and has not much appetite, yet in essential points there is a great improvement : the complaint is better, she takes little medicine, she is stronger, and walks and sleeps better." Next comes an account of in-door amusements - "glee-singing, tableaux vivants, German cotillons, charades, a play and Shakspeare readings once a week, with a concert now and then." Of Mr. (Case 10) the letter says: "You would be surprised at the change in him; he looks, and is, wonderfully better, and takes part in all the entertainments in the most vigorous manner. ...... Mr. $X$. also [my former correspondent, T. C. A.] looks quite a different man to what he did. Mrs. $X$. was telling us to-day how much and how steadily he was improving in health. Most of the invalids in this house are making good progress, except poor Mr. — (Case 7), who is very ill, and an Italian lady, whom the doctor has sent away."

These letters give some pleasant insight into the winter life at Davos; and the remarks of Mr. X. on the evil of stuffy rooms are most important when considered in the light of the aseptic hypothesis. Not only so, but I have ventured to urge upon the Kurverein in the strongest manner the duty of securing pure air both within and without the houses. I believe the Verein is in some measure alive to this; scarcely sufficiently so; yet it is a vital point. Let the district once be saturated with sewage, and the virtues of Davos may vanish. Of the manuring of the meadows, I am assured that this is almost all done at snowmelting, when no patients are in Davos. Then the winter's dung is put out. The October dressing is a limited affair, as the cows have lived all summer in the Alps, and there are no great accumulations. During the snow-melting the visitors depart to Italy or to Baden-Baden.

To those who are thinking of passing the summer at Davos, I would advise that they leave England as the summer begins, travel slowly through the continent, stop a few nights at Ragatz, and arrive at Davos about June 20th. Leeds. 